\title{
PARA ALÉM DO LIVRO E DA SALA DE AULA: A CONTROVÉRSIA DOS AGROTÓXICOS NA PRÁXIS DA PEDAGOGIA DA ALTERNÂNCIA
}

\section{MARIANA PETRI}

Instituto Federal do Espírito Santo (Ifes)

E-mail:maripetri_bio@yahoo.com.br

\section{ALEXANDRE BRASIL FONSECA}

Universidade Federal do Rio de Janeiro (UFRJ)

E-mail: coloquio10@gmail.com

\section{RESUMO}

Este trabalho visa a apresentar vivências e reflexões a partir de uma pesquisa etnográfica junto a educadores e estudantes de uma Escola Família Agrícola (EFA) no Estado do Espírito Santo (ES), cujo trabalho pedagógico é orientado pela Pedagogia da Alternância. O acompanhamento de uma turma de 14 estudantes do 4ㅇano Técnico em Agropecuária, numa dinâmica entre Tempo-escola e Tempocomunidade, na elaboração e realização de um Plano de Estudo com a temática da olericultura (convencional e orgânica) nos permitiu observar os atravessamentos que a imersão com a realidade local viabiliza na formação dos técnicos agrícolas da EFA, favorecendo a formação crítica e engajada dos futuros profissionais. O debate sobre o uso de agrotóxicos, a produção de conhecimento sobre a temática para tomada de decisões são ampliados pela incorporação de saberes outros, mergulhados nas questões culturais, econômicas e sociais da realidade local.

\section{PALAVRAS-ChaVE:}

Controvérsia sociocientífica; Dialogicidade; Agrotóxicos; Alternância; Escola Família Agrícola.

\section{BEYOND THE BOOK AND THE CLASSROOM: THE CONTROVERSY OF PESTICIDES IN THE PRAXIS} OF PEDAGOGY OF ALTERNATION

\section{ABSTRACT}

This work aims to present experiences and thoughts based on an etnographic research with educators and students from an Agricultural Family School (EFA, in Brazil) in the State of Espírito Santo (ES), whose pedagogical work is guided by Pedagogy of Alternation. The accompaniment of a group of 14 students of the 4th year of the Technical Course in Agriculture, in a dynamic between School-Time and Community-Time, in the elaboration and realization of a Study Plan with the thematic of olericulture (conventional and organic) allowed us to observe crossings that immersion with the local reality makes possible in the training of EFA agricultural technicians, favoring the critical and engaged training of future professionals. The debate on the pesticides use and the production of knowledge as a basis for decision-making are amplified by incorporation of farmers knowledge, immersed in the cultural, economic and social issues of the local reality.

\section{KEYWORDS:}

Socio-scientific controversie; Dialogicity; Pesticides; Alternation; Agricultural Family School. 


\section{INTRODUÇÃO}

Uma educação científica para além do modelo tradicional-tecnicista vem sendo debatida e proposta por diferentes linhas de pesquisa e pensamento dentro da educação em Ciências, como a educação Ciência-Tecnologia-Sociedade-Ambiente (CTSA), especialmente quando voltada às Questões Sociocientíficas (QSC).

Questões Sociocientíficas são baseadas em problemas ou situações controversas e complexas que exigem, para sua análise, não apenas os conhecimentos científicos, mas também aspectos éticos e políticos para a tomada de decisões, mobilizando valores, habilidades e atitudes (CONRADO e NUNES-NETO, 2018).

O uso de agrotóxicos vem sendo considerado como um tema controverso (FERNANDES e STUANI, 2015) e, no campo da educação em Ciências, aparece ora como uma QSC, dentro da abordagem CTS ou CTSA (LOPES e CARVALHO, 2012; ABREU, STAUDT, RIBEIRO e FREITAS, 2015; ANDRADE, CONRADO, NUNES-NETO e ALMEIDA, 2016; ANDRADE, NUNES-NETO e ALMEIDA, 2018) - ou Controvérsia Sociocientífica (CSC, em FONSECA, DUSO e HOFFMANN, 2017) -, ora numa abordagem relacional entre o movimento CTS(A) e a abordagem temática freiriana (SOUZA e MARQUES, 2017; SOUSA e GORRI, 2019).

A despeito das supracitadas propostas para inserir a temática em sala de aula, ela ainda é pouco abordada no ensino e está presente em poucos livros didáticos (FERNANDES e STUANI, 2015), com indicativos de que, quando considerada, ocorre de maneira fragmentada, descolada de seu contexto social e histórico (SOUSA e GORRI, 2019).

Em se tratando do tema no contexto da Educação do campo, que não se dispõe a apenas reproduzir/aplicar os conhecimentos sistematizados da área do Ensino de Ciências (EC), mas busca um projeto de educação transformadora, pensada a partir das especificidades e diversidade dos contextos locais, e das demandas concretas da 
realidade do campo (CALDART, 2009; BRICK, PERNAMBUCO, GOUVÊA e DELIZOICOV, 2014), tratar sobre agrotóxicos implica fazer da escola um local de problematizações e intermediações entre a realidade vivida na comunidade, com sua complexidade e seus constrangimentos, com o cabedal de conhecimentos acadêmicos sobre a questão.

Alguns autores pontuam, para a construção de novos parâmetros para uma educação científica que ampliem a participação na tomada de decisões, a crítica e a transformação da realidade, a aproximação com postulados freirianos (AULER, 2011), tomando como exemplo a abordagem temática, para uma educação científica que se aproxime e esteja a serviço do projeto de Educação do campo (BRICK et al., 2014).

As Escolas Famílias Agrícolas (EFAs), implantadas no Brasil a partir do Movimento de Educação Promocional do Espírito Santo (MEPES), no ano de 1969, vêm experimentando um percurso educativo estruturado em "Temas Geradores", de interesse do mundo camponês, graças à forte influência que as ideias de Paulo Freire tiveram durante a implantação dessas unidades escolares (ZAMBERLAN, 2018). Aliados à Pedagogia da Alternância, que intercala tempos escolares (TE) com tempos junto à família/comunidade (TC), seus variados instrumentos pedagógicos possibilitam uma leitura e análise reflexiva sobre a realidade local: a imersão no TC funciona como fonte de conhecimentos, ponto de partida e de chegada do processo de aprendizagem, e como caminho educativo (GIMONET, 1999, p.45). Trata-se de uma estratégia de ensino que favorece análises mais abrangentes dos contextos sociais, econômicos e ambientais locais e, por conseguinte, a tomada de decisões embasadas não somente nos livros e discussões em sala de aula, mas a partir da leitura do mundo concreto no qual estão inseridos os educandos.

O objetivo deste trabalho foi investigar como a temática dos agrotóxicos é abordada no contexto educacional da Pedagogia da Alternância numa Escola Família Agrícola, a fim de compreender como o diálogo (FREIRE, 2011) com os camponeses 
(inclusive os estudantes), e com a sua realidade, são considerados em sala de aula, a partir de vivências do Tempo-Escola e do Tempo-Comunidade de uma turma no ano final do Curso "Técnico em Agropecuária com qualificação em hortifruticultura orgânica".

\section{Percurso Metodológico}

\subsection{ConteXto Local E A EFA SÃo JoÃo do GaRRAFão}

A Escola Família Agrícola São João do Garrafão (EFASJG) está situada no município de Santa Maria de Jetibá (SMJ, na região central-serrana do ES), colonizado por pomeranos, que constituem um dos Povos e Comunidades Tradicionais do Brasil (Decreto 6.040/2007; BRASIL, 2007). De tradição agrícola familiar, os pomeranos se adaptaram aos cultivos locais. Atualmente, o município é destaque na produção de ovos e na produção agrícola (trata-se do maior hortifrutigranjeiro capixaba), sendo a olericultura a atividade que melhor se distribui (JACOBSON et al., 2009). Embora existam produtores que cultivem hortaliças com bases agroecológicas e sustentáveis, a grande maioria adota técnicas convencionais e faz uso abusivo de agrotóxicos e demais insumos agrícolas, havendo muitos relatos de intoxicação humana por agrotóxicos (CHISTÉ e CÓ, 2003).

Desde a sua criação, em 1990, a EFASJG prezou pela família rural e a produção ecologicamente correta, mas o ensino profissionalizante teve início apenas em 2000, com o curso "Técnico em Agropecuária com qualificação em hortifruticultura orgânica", integrado ao Ensino Médio (PDI, 2016). A escola oferece atualmente o Ensino Fundamental e Médio (com opção profissionalizante), funcionando no regime da Pedagogia da Alternância (PA). Os alunos intercalam uma semana de aprendizado nas dependências da escola e uma semana de aprendizado em meio aos agricultores e agricultoras, desenvolvendo seus estudos com instrumentos próprios da PA, tais 
como o Plano de Estudo (PE), o Caderno da Realidade, a Folha de Observação, além de atividades específicas das disciplinas.

\subsection{Percurso Etnográfico}

Trata-se de uma pesquisa qualitativa, com abordagem etnográfica, reconhecendo as marcas da subjetividade na pesquisa e a complexidade dos fenômenos sociais. Essa abordagem nos auxilia a compreender os fatores socioculturais mais amplos que afetam a dinâmica escolar (ANDRÉ, 2012) na EFASJG e, ao mesmo tempo, a dinâmica de interseção entre escola e comunidade. Para as pesquisas relacionadas às escolas do campo, que utilizam a Pedagogia da Alternância, a abordagem etnográfica se apresenta como uma opção interessante (SILVA e GONÇALVES, 2018), pois a alternância possui instrumentos pedagógicos próprios e específicos, ligados à realidade da vida no campo e ao princípio de que a Educação deve ser realizada em dois espaços-tempos que se interseccionam e complementam.

Em nosso processo de pesquisa, iniciamos o acompanhamento das atividades da EFASJG a partir da primeira semana de aulas do ano letivo de 2020. Para a construção dos dados apresentados, acompanhamos uma turma de 14 alunos do 4을 ano do curso técnico em Agropecuária, durante três semanas. Da primeira semana, narramos a dinâmica de elaboração do Plano de Estudos (o PE), o levantamento de hipóteses, a construção de perguntas pelos estudantes e a confecção final do roteiro do PE, com os pontos de observação e as perguntas a serem realizadas juntos aos agricultores no Tempo-comunidade ("Momento 1").

Na segunda semana, no transcorrer do Tempo-comunidade, acompanhamos dois grupos de estudantes (total de 8 alunos/as da turma) em suas atividades de visitação às propriedades convencional e orgânica. As visitas de cada grupo ocorreram em dias distintos, ambas na parte da tarde. Os dados referentes às atividades do Tempo-comunidade compõem, em nossos resultados, o "Momento 2". 
Da terceira semana, de volta ao Tempo-escola, narramos o processo de compartilhamento das informações obtidas junto aos agricultores e agricultoras, no momento da "Colocação em comum", realizada durante todo um dia de aula e mais uma parte de uma manhã, resultando na elaboração coletiva de uma "Síntese", a partir das informações obtidas junto à comunidade. Agrupamos os dados deste Tempoescola como "Momento 3", a qual adicionamos a leitura e análise do texto da "Síntese" produzida coletivamente pelos estudantes em sala de aula.

Os "momentos" foram acompanhados utilizando-se a técnica da observação participante, fotografados e registrados em diário de campo. A análise dos dados foi realizada mediante análise interpretativa, tendo, como lente de leitura, a dialogicidade (FREIRE, 2011), buscando elementos nos relatos e comportamentos dos sujeitos que indicassem - ou não - a abertura ao diverso, ao diálogo, à exposição dos diferentes pontos de vista, e à construção da temática dos agrotóxicos em sua complexidade, embebida de práticas e percepções sobre a realidade local.

O trabalho de campo com os sujeitos da pesquisa foi devidamente aprovado pelo Comitê de Ética em Pesquisa da Universidade Federal do Rio de Janeiro (UFRJ), do processo número 24571319.2.0000.5286, e segue os procedimentos de autorização, pelos seus sujeitos, para apresentação dos dados fornecidos. Em atendimento a isso, mantivemos o anonimato de todas as pessoas envolvidas.

\section{RESULTADOS E DISCUSSÃO}

Optamos, em relação à apresentação dos relatos de campo, pela narrativa em primeira pessoa, com detalhamento das percepções da pesquisadora, próprio do registro etnográfico. Destacamos, em quadros, relatos que consideramos mais relevantes para nossa análise, no entanto incluímos outros no decorrer do próprio texto. 
3.1 Momento 1: Tempo-Escola - Primeiros Contatos, Motivação, Construção de Hipóteses

A EFA São João do Garrafão fica a cerca de 120 km da cidade de Vitória/ES, de onde parti naquela manhã, num trajeto cheio de curvas e montanhas, para iniciar minha própria travessia etnográfica. Após a chegada, logo fui apresentada à turma do 4o ano Técnico, com a qual passei o restante do dia e das próximas semanas. Eram em total de 14, sendo 8 meninas, e 6 meninos, entre 17 e 19 anos. Estavam sem uniformes, sentados em semicírculo e participavam ativamente da aula da manhã, sobre a elaboração de seus Projetos Profissionais (o chamado PPJ: Projeto Profissional do Jovem), que funcionam como um trabalho final do curso técnico.

Na tarde daquele primeiro dia, fui convidada a participar da aula de "Motivação" para o Plano de Estudos. O monitor orientador da turma, ao entrar na sala, foi ao quadro e escreveu:

\section{T.G.: Produção Orgânica}

\section{P.E.: Olericultura}

A primeira sigla significa "Tema gerador" (T.G.) e a segunda "Plano de Estudo" (P.E.). Na prática, o Tema Gerador "Produção Orgânica" norteará os Planos de Estudo para o $1^{\circ}$ e 2 o bimestres no 4ㅇa ano técnico, sendo realizado um Plano de Estudo para cada bimestre, totalizando 4 ao ano. As diretrizes para a elaboração do primeiro PE seriam realizadas naquele momento, durante a etapa de "Motivação", que funciona como um momento de reflexão e problematização para as etapas seguintes.

A Motivação é realizada de diferentes maneiras, dependendo do monitor responsável e incluindo linguagens artísticas, quando assim se deseja. Ali, naquele dia, a dupla de monitores apresentou utilizando o recurso do Datashow, imagens das práticas de olericultura na região, incentivando a participação dos alunos sobre o que podiam observar e comentar a cada imagem que aparecia. 
As primeiras imagens e comentários diziam respeito à diversificação das culturas praticadas e à inclinação do relevo, visto tratar-se de uma região serrana. No segundo slide, destacou-se o trabalho familiar, independentemente da idade (uma das imagens mostrava uma criança bem pequena ao lado de uma família em atividade na roça, numa estrutura de madeira conhecida como "chiqueirinho"). O professor perguntou quantos ali já tinham sido levados para o trabalho junto com os pais e a maioria dos estudantes afirmou que sim, embora em estruturas diferenciadas. $O$ trabalho feminino também foi destacado, pois uma das características marcantes dentre os pomeranos é a participação feminina na lida na roça.

Num terceiro slide apareceu a questão do preparo do solo, com imagens de tratores "pelando" topos de morro para prepará-los para o cultivo. O monitor destacou que as olerícolas, por possuírem ciclo de vida curto, são cultivadas até quatro vezes ao ano, chamando atenção para a quantidade de vezes em que seria necessário o preparo do solo para o cultivo e o desgaste associado a isso. Os alunos também destacaram a ausência de mata nos topos de morro e um aspecto cultural importante na região: se uma área para cultivo não estiver bem "limpa", os agricultores consideram que foi realizado um "trabalho de preguiçoso", e que se trata de uma "cultura suja".

O quarto slide apresentava imagens de trabalhadores rurais aplicando agrotóxicos nas lavouras e os alunos comentaram sobre a ausência dos equipamentos de proteção individual (EPIs) pelos trabalhadores nas imagens e a sua não utilização por parte dos alunos: um deles relatou ter aplicado o glifosato "Roundup" muitas vezes apenas de bermuda. Também falaram sobre um novo decreto que obriga agricultores a trocar seus equipamentos a cada três meses, e a eficácia ou não disso. Quando perguntados se tinham na família algum caso de impacto severo em relação ao uso de veneno, apenas um dos estudantes disse ter perdido um tio quando este ainda era criança, por ter tirado do pé e comido um tomate poucas horas depois da aplicação de veneno. Segundo relatos de seu pai, o tio teria morrido intoxicado. 
Depois, o monitor responsável, a partir das imagens usadas para problematização, passou a apresentar os desafios/ possibilidades para uma agricultura sustentável na região, como a utilização de consórcios de plantas, estufa, diversificação em escalas menores ao que hoje é praticado na região, e a necessidade de tecnologia para melhorar a produtividade e a qualidade de vida do produtor rural. A olericultura foi citada como uma atividade que castiga muito o trabalhador devido aos cuidados que demanda.

Para finalizar a fase de motivação, o monitor apresentou um gráfico sobre o percentual de resíduos de agrotóxicos em inúmeros alimentos, chamando atenção para o fato de muitos utilizarem veneno acima do permitido ou que não possuem registro para determinados cultivos. Os alunos confirmaram, citando exemplos de venenos que estão acostumados a verem ser utilizados em cultivos inapropriados. Por fim, encerrando aquele momento em sala, o professor lançou três hipóteses de trabalho para os estudantes, que deveriam servir de guia para a próxima etapa que realizariam a seguir:

1. A participação da olericultura na região é expressiva;

2. A olericultura tradicional causa degradação;

3. A olericultura orgânica é uma opção para maior qualidade de vida dos produtores e consumidores.

Apesar do posicionamento favorável à agricultura sustentável, ao colocar essas hipóteses em questão, os monitores deixaram claro que todas elas deveriam ser confrontadas com a realidade. Ou seja: seria necessário pesquisar como as famílias de agricultores locais enxergam essas questões, para trazer o debate para a sala de aula. De que o mais importante seria entender a percepção dos agricultores. Segundo um monitor: "Somente quem pode falar sobre isso - a qualidade de vida do produtor orgânico - é o próprio produtor". Na semana seguinte, no período caracterizado como 
Tempo-comunidade (ou Tempo-família), os estudantes deveriam se organizar para visitar um produtor convencional e um produtor orgânico, para observar a realidade e responder às questões que seriam formulados como roteiro do Plano de Estudo.

O momento seguinte à Motivação constituiu separação em três grupos para elaboração do roteiro do PE, que durou cerca de uma hora: os estudantes deveriam formular o "chapéu" (texto introdutório sobre cada tema) e as perguntas norteadoras. Um grupo trabalhou na própria sala e os outros buscavam outros locais na escola: um corredor com bancos e o jardim. Pude acompanhar um pouco do desenvolvimento de cada grupo, bem como perceber a autonomia dos alunos. Buscavam sobre o tema em suas anotações da aula de Horticultura do dia anterior, debatiam entre si e elaboravam listas de questões sobre o que poderiam perguntar na aula de campo. Ao final do tempo dedicado à atividade, cada grupo entregou um texto e a lista de questões. Posteriormente, os professores iriam sintetizar os textos na elaboração final de um "chapéu" único e uma lista única de perguntas para todos, a ser entregue ao final daquela semana, para levarem para casa.

3.2 Momento 2: Tempo-Comunidade - Visita e Entrevista em Propriedades Convencionais e ORGÂNICAS

Acompanhei dois grupos nas visitas do Tempo-comunidade na semana seguinte. Cada um deles deveria visitar uma propriedade convencional e uma propriedade orgânica, tirar fotos dos cultivos e entrevistar um agricultor e, também, comparar as respostas de produtores convencionais e orgânicos. Por questões de espaço neste artigo, limitarei a apresentação dos contextos e relatos mais importantes, no que tange à utilização dos agrotóxicos, em cada propriedade visitada.

O primeiro grupo, formado por três alunas, visitou as propriedades $A$ e $B$, sendo a primeira convencional e a segunda uma propriedade orgânica. Aproveitaram a propriedade da família de uma das estudantes para recolher as informações sobre 
agricultura convencional. O dia estava chuvoso e chegar até lá só seria possível de carro. O pai de uma outra estudante se encarregou de transportá-las (e a mim) até lá. Iriam fazer uma visita técnica, fotografar, mas a entrevista seria com o avô da aluna, que esperava o grupo em sua casa, no Centro da cidade. No carro, no caminho, fomos alertados pela aluna que guiava:

Olha, gente, se estiverem "puvorizando" lá vocês não liguem, tá? Só na sextafeira que pedi pra eles não "puvorizarem" mesmo, porque os professores vêm visitar o meu projeto... E eles falam tanto pra nóis, né, que isso não tá certo... Na sexta pedi pra todo mundo ficar quietinho pra eu não passar vergonha. (Estudante A, em 12 de fevereiro de 2020. Fonte: Diário de campo).

$\mathrm{Na}$ sexta-feira seguinte a aluna receberia visita dos monitores para acompanhamento do seu Projeto Profissional e por isso havia solicitado aos trabalhadores da propriedade do pai (meeiros), que não pulverizassem agrotóxicos na frente dos monitores que lá iriam.

Visitamos o que foi possível apesar da chuva. A aluna anfitriã, que estava cuidando de seu irmão mais novo, orientava a parar o carro em alguns pontos, para observarem a plantação e fotografarem para a apresentação na semana seguinte, no Tempo-escola. No retorno ao Centro, um meeiro da propriedade passou por nós segurando as bombas de veneno, de bermuda e chinelo. O "jeito" dos agricultores realizarem a pulverização, sem qualquer proteção, foi assunto no carro.

A entrevista foi realizada na cozinha da casa do avô, no Centro do vilarejo. Quando chegamos, ele aguardava as meninas. O avô contou que aquela propriedade fora comprada há 15 anos e ali havia café e alguns outros cultivos, antes das olerícolas. A neta assumiu o lugar de quem faria as perguntas, que partiam do roteiro entregue ao final da semana anterior, como guia para o PE. No início as questões eram dirigidas ao avô, que as respondia (não sem certa intervenção da neta) e, ao final, talvez pelo acelerar da hora, talvez por ser uma prática comum, ela mesma já ia respondendo ao questionário em voz alta enquanto a outra aluna também anotava as respostas. 
Pareceu que isso ocorria porque a estudante $A$ já sabia das respostas por se tratar de sua propriedade. Às vezes o avô era chamado a complementar a resposta e as alunas anotavam com rapidez - e termos técnicos (porque é uma obrigatoriedade nos registros) - que certa feita o avô chegou a dizer que "Pra vocês que estuda é mais fácil de responder essas coisa..." (e as deixou respondendo e escrevendo sozinhas e saiu para atender ao telefone...).

A riqueza das possíveis repostas do avô foi perdida na busca em responder ao questionário com as respostas (técnicas) já conhecidas pelas alunas. Por isso, na EFA, é comum não permitir, nos anos finais, que os estudantes façam as entrevistas em suas próprias propriedades. Quando não observado o caráter da dúvida sincera e abertura ao conhecimento dos agricultores - a fim de gerar conhecimento novo -, nem sempre a dinâmica com a comunidade pode ser aproveitada pelos estudantes.

O Quadro 1 destaca as respostas do avô que chamaram atenção em relação ao uso de agrotóxicos; a temática apareceu em diferentes momentos e levantou discussões diversas: sobre novos agrotóxicos no mercado, sobre o uso da palavra agrotóxico (o avô questionou qual era o termo técnico correto e lembrou, em tom de dúvida, se não deveria ser "defensivo"), sobre o papel das empresas locais, etc.

Quadro 1: Relatos de agricultor convencional, avô de aluna da EFA, entrevistado para o PE em 12 de fevereiro, 2020 (Agricultor A). Fonte: Diário de campo.

Agricultor A - [...] Cada ano vai mudando o produto (os "defensivos"); vão criando variedades pra vender; a Stuhr, a Discher*... Na verdade, parece até os mesmos produtos, mas vão inventando pra vender". (*Empresas de venda de insumos e máquinas do setor agropecuário).

Sobre visitas técnicas, uma das perguntas do roteiro do PE:

Agricultor A - [...] Antes era a COOPEAVI; agora são as empresas, a Stuhr.

Estudante A (neta) - Ano que vem vai ser eu; fala com orgulho.

Agricultor A - É... porque tem que ajudar nóis, não os otro.

Estudante $\mathrm{A}$ - Porque esse pessoal só vem aí pra vender.... 
Sobre melhorias para o futuro, uma das perguntas do PE, o avô relata o desejo de devolver corretamente as embalagens de agrotóxicos:

Agricultor A - [...] A gente tem que devolver certo as embalagens. Isso tem que fazer, é obrigatório. Estudante A - Vimos o meeiro lá na roça de chinelo e bermuda...

Agricultor A - Ele tem o equipamento, mas não usa. Tem que ter, senão nóis é multado.

Estudante A - Eu falei pra elas (se referindo a mim e outras integrantes do grupo) que ia chegar lá em cima e dizer pra todo mundo que era o ldaf* chegando... Eles iam correr tudo pra botar a roupa, comentário que fez as estudantes e o avô gargalharem. (*Instituto de Defesa Agropecuária e Florestal do Espírito Santo).

O percurso para a propriedade orgânica foi difícil, havia chovido muito e o caminho era íngreme e sinuoso; o próprio responsável avisou por mensagem que achava que não daria para subir. Ao meu lado, os comentários eram de que "o problema desses sítios orgânicos é que eles precisam ser muito isolados, têm que ficar o mais longe possivel do veneno; ficam sempre nessas grotas". Não é mesmo muito fácil acessar esses lugares...

Seguimos para lá em dois carros: o do avô da estudante A e do pai da estudante B, ambos como motoristas. A terceira aluna chegou à propriedade levada pelo namorado, de motocicleta. Sem o apoio das famílias seria impossível a realização das visitas para os Planos de Estudo, para muitos estudantes. As propriedades são longe e sem acesso via transporte público. Na chegada à propriedade orgânica, todos se cumprimentaram. Os mais velhos - o pai, o avô, e o Agricultor B - demonstraram já se conhecerem, cumprimentaram-se e conversaram em pomerano. Depois, as estudantes foram convidadas a entrar na casa do anfitrião para a entrevista, enquanto os demais permaneceram do lado de fora aguardando.

A entrevista durou mais de uma hora. Agricultor B ia seguindo o roteiro e as perguntas das alunas, mas suas respostas o levavam a novos temas. Impressionou-nos saber que ele havia iniciado as primeiras movimentações para o plantio de orgânicos 
em 1985. Ou seja, tratava-se de um dos pioneiros no plantio de orgânicos do município

e ajudara a fundar a primeira Associação, algo que foi surpresa para as estudantes.

Muitos de seus relatos são relevantes para compreender os desafios da produção orgânica no município. Destacamos, no Quadro 2, aqueles que consideramos mais relevantes.

\section{Quadro 2: Relatos de agricultor orgânico, entrevistado para o PE em 12 de fevereiro, 2020} (Agricultor B). Fonte: Diário de campo.

Agricultor B - [...] Entrar como orgânico hoje é muito fácil... Naquela época vinha um técnico do Rio Grande do Sul só de três em três meses pra nos ajudar. Eu colocava as verdura tudo numa bicicleta e saía vendendo, até que conseguimos abrir uma loja em Vitória.

[...] Pra virar agricultor orgânico é preciso mudar, primeiro, a cabeça. Depois, a propriedade. Você não consegue colher logo em seguida, o veneno mata os bichos... Precisa de um ou dois anos pelo menos pra recuperar.

[...] A gente não queima, não ara morro abaixo, não joga herbicida em nada, a gente realmente cuida. Preserva o que tem e ainda refloresta.

[...] A assistência técnica é feita pelo Incaper, eles vêm do escritório local de Santa Maria. Fazem visita semestral ou de acordo com a necessidade. Mas eles dizem que tá difícil fazer a visita, que o governo não tá ajudando financeiramente mais. O Sindicato também ajuda as vezes com alguma questão.

[...] As vantagens do orgânico são, primeiro, a sua saúde, a saúde da sua terra e a saúde de quem consome. Criamos três filhos (e neto) que nunca pararam em hospital por causa de diarreia ou algum problema por causa do veneno. Você vai na roça, colhe lá e come direto, sem se preocupar com intoxicação.

[...] Não tem nenhuma desvantagem. Isso é só vantagem. Apesar das dificuldades, de tudo ser mais dificil pra quem quer produzir orgânico, a gente fica muito alegre que a gente tá com saúde e o freguês da gente também. Tenho freguês de 29 anos... São honestos, só compram da gente. Pergunta quando vai ter o produto. Espera produzir. Mas é claro que também tem o freguês que compra orgânico dependendo do preço e ainda reclama que tá "feio".

[...] A comercialização está cada vez mais difícil por causa da burocracia.

[...] Na feira, que é nosso principal lugar de venda, tá difícil vender os doces, o mel que a gente produz. A fiscalização tá batendo, tá multando todo mundo, o dia que eles passarem eles dizem que recolhe, mas o meu eles não levam não... Do jeito que eles querem, a gente não consegue atender não. $O$ agricultor até tenta fazer tudo direitinho e eles ainda dizem que não tá bom.

Apesar de o Agricultor B realçar as inúmeras vantagens da produção orgânica, com certa paixão e orgulho pelo seu trabalho, ele pontua uma série de desafios para 
quem escolhe produzir de maneira sustentável, destacando que a regularização dos minimamente processados e sua fiscalização nas feiras livres é, atualmente, um dos principais desafios.

Logo depois da entrevista, o Agricultor B levou todo o grupo de visitantes para conhecerem a propriedade, o que incluía a mim e aos parentes das estudantes que o haviam entrevistado: avô, pai, irmão, namorado. Atentos e curiosos às técnicas sustentáveis que ele apresentava, a visita para o PE se transformou num espaço-tempo de aprendizagem entre agricultores, que ouviam e aprendiam entre si, e entravam em contato com as práticas e o conhecimento que o Agricultor B narrava sobre caldas, compostagem, manejo agrícola orgânico etc.

No dia seguinte, acompanhei outro grupo, de cinco estudantes, a outras duas propriedades: uma convencional e outra orgânica, bem próximas uma da outra. Os estudantes estavam de moto, o que é bem comum no interior. Da casa de uma das estudantes, que marcaram como ponto de encontro, partiram para a propriedade convencional, do Agricultor C, o qual aguardava o grupo e conhecia a dinâmica do PE: havia sido aluno da EFASJG. Por ser técnico agropecuário, formado pela EFA, a prática do Agricultor C, apesar de não orgânica, guardava algumas peculiaridades. Ele passou a buscar alternativas mais sustentáveis em seus cultivos, apesar de não ter aderido a todas as especificações dos orgânicos.

Na busca por produtos e técnicas menos agressivas, passou a utilizar e tornouse o representante local de uma marca de fertilizantes especiais e orgânicos. Ele pratica a chamada agricultura convencional, porém utiliza o mínimo de produtos nocivos, de acordo com suas necessidades e possibilidades, inclusive fazendo experimentações do que é efetivo, ou não (Quadro 3). 
Quadro 3: Relatos de agricultor convencional, entrevistado para o PE em 13 de fevereiro, 2020 (Agricultor C). Fonte: Diário de campo.

Agricultor C - [...] A pulverização aqui eu só faço quando é realmente necessário. Uso, por exemplo, produto registrado pra controlar broca. Mas apenas quando preciso e os que têm registro pros meus cultivos. Ouço de gente que usa produto que é pra outras culturas. Aqui faço calagem, uso bastante esterco líquido e sólido, uso cálcio e boro via foliar, óxido de potássio, enxofre... (e continua citando a lista de produtos especiais e orgânicos que utiliza como fertilizante, e para o controle de pragas e doenças).

[...] De maneira convencional, a gente tem mais facilidade pra tá produzindo e controlando praga e doença. Se fosse orgânico, eu sozinho não daria conta do tanto que eu produzo.

[...] A desvantagem é o agrotóxico, né? Se tivesse como, seria bem melhor sem, né? Nem precisaria discutir isso....

[...] Eu já pensei em mudar pro orgânico. Aí pensei de novo. De novo. De novo. Aí pensei: não. Porque o orgânico é muito puxado; a mão de obra. - Ao que uma das estudantes confirmou.

A outra propriedade visitada por este grupo realizou a transição para a agricultura orgânica em 2004 e comercializa variados produtos, inclusive de fabricação da agroindústria familiar, além de, em anos anteriores, ter recebido visitantes para o agroturismo (Quadro 4).

Quadro 4: Relatos de agricultor orgânico, entrevistado para o PE em 13 de fevereiro, 2020 (Agricultor D). Fonte: Diário de campo.

Agricultor D - [...] "O maior problema dos orgânicos sempre foram os insumos. Até hoje o adubo orgânico é um problema".

[...] Tudo no orgânico que você usa, tem que respeitar. Eu uso vários produtos biológicos. Quando tenho dúvidas sobre algum produto, comunico à certificadora e pergunto se pode. Também uso muito uma calda produzida aqui mesmo, com talo de banana, esterco e cinza.

[...] A assistência técnica é feita pelo Incaper, mas é de "fingir", né? Porque eles não têm tempo. São 160 propriedades orgânicas em Santa Maria de Jetibá. Eles dão prioridade às propriedades orgânicas, mas não dão conta. A vantagem é que meu irmão é técnico pela EFA e entende bastante coisa. De concreto mesmo tem o apoio do SEBRAE, que banca $70 \%$ do custo da certificação.

[...] As maiores dificuldades são com a burocracia pros orgânicos. E tem também a sazonalidade dos produtos. O consumidor não entende a sazonalidade. Seria bom se conseguíssemos fazer o ano todo pra atender ao mercado. No convencional tem produtos que conseguem controlar isso. A vantagem é que é muito raro não conseguir comercializar a produção. Vende direto ao consumidor e é a gente que define o preço, não o mercado. 
O Agricultor D, orgânico, apresenta uma visão mercadológica muito maior que o Agricultor B, para quem a produção orgânica é quase uma filosofia de vida. Ele também relata o problema com a fiscalização, uma questão que está preocupando a muitos dos agricultores e agricultoras do município e às Associações.

\subsection{Momento 3: TeMPO-EsCOLA - ColocaÇÃo em COMUM e SínTESE}

Na semana seguinte, de volta ao Tempo-escola, era momento de compartilhar o que foi visto nas visitas às propriedades e colhido nas entrevistas, atividade chamada de "Colocação em comum". Cada grupo ia respondendo oralmente às questões do PE e uma aluna assumiu a tarefa de redigir um texto comum a todos, com auxílio do computador e do Datashow, que projetava o texto para que todos lessem e dessem sugestões de modificação. Era nítida a autonomia e destreza de escrita da aluna que assumiu a tarefa, demonstrando capacidade de síntese de ideias. Todos os alunos participavam da intervenção, com exceção de um ou dois estudantes mais tímidos, que hora ou outra eram interpelados pelo monitor. O texto era uma criação coletiva, dos 14 estudantes e do monitor, que aproveitava o momento para elaborar conceitos junto com os alunos.

Esse momento era aproveitado também pelo monitor para anotar as dúvidas que surgiam durante a elaboração do texto e que não poderiam ser trabalhadas naquele momento, mas depois seriam repassadas a outros monitores das disciplinas específicas (como se tratava do 4ㅇa ano técnico, para professores-monitores da área técnica).

A “Colocação em comum” durou um dia e boa parte de uma manhã. O objetivo final era a elaboração de uma "Síntese", que depois seria impressa e entregue a cada aluno, para constar em seu "Caderno da Realidade". O que impressionava, no texto que estava sendo elaborado coletivamente, é que as informações ali descritas nada mais eram que informações da realidade local, vistas, percebidas, questionadas e 
registradas pelos estudantes. Não se tratava de conteúdo pronto. Ao mesmo tempo, no momento em que os estudantes traziam ao monitor as informações, este mediava o debate e o enriquecia com perguntas e problematizações. Isso condiz com a proposta de Freire, para quem a tarefa do educador é a de problematizar aos educandos o conteúdo que os mediatiza, e não a de dissertar sobre ele, de dá-lo, de estendê-lo, de entregá-lo, como se se tratasse de algo já feito, elaborado, acabado, terminado (FREIRE, 1983, p.56). Essa vivência do diálogo em torno de uma temática, no entanto, não deve ser feita de maneira descomprometida, mas com o empenho do educador para a constante transformação da realidade.

Surgiu, naquele momento, a problematização em relação ao uso dos equipamentos de proteção individual (os EPIs) pelos produtores convencionais e o retorno das embalagens de agrotóxicos. Em algumas respostas anotadas pelos estudantes, agricultores relatavam que desejavam ou tentavam usar tais equipamentos e retornar as embalagens e o monitor aproveitava para questionar, num âmbito mais amplo, como de fato essas questões eram tratadas na região. Essas discussões eram complementadas por conhecimentos técnicos dos monitores, que tornavam o momento muito rico em discussões.

Outros temas que geraram debate foram a assistência técnica, especialmente a venda "empurrada" de produtos por técnicos de empresas privadas e o uso de termos como defensivos - usado por quem admite e apoia o uso dos agroquímicos - e agrotóxicos - empregado por aqueles que lhes são contrários. Essa discussão apareceu no momento da redação do texto e o monitor explicou as diferenças conceituais entre os termos, momento em que um dos estudantes afirmou: "pra mim é defensivo mesmo", deixando claro o posicionamento de muitos dos alunos em relação ao uso dos agroquímicos, prática que a escola tenta combater, mas sem impor mudanças aos alunos ou a suas famílias. 
A importância da EFASJG nas mudanças na dinâmica de produção da região também acaba aparecendo nos relatos: um grupo visitou uma propriedade orgânica de município vizinho e relatou que o motivo da mudança para orgânicos foi porque o filho do casal de agricultores havia feito o Técnico na escola, procurou entender o mercado e resolveu propor a mudança para os pais.

Todas as informações colhidas com os agricultores de cada grupo foram incluídas no texto final, inclusive as divergências entre os entrevistados. O momento final foi marcado pela elaboração de uma conclusão em conjunto, tomando como base as hipóteses iniciais e os resultados obtidos com as visitas à comunidade. Tomei notas do penúltimo parágrafo:

A olericultura é uma atividade muito importante para a economia da região, principalmente para os agricultores familiares. Os produtores orgânicos manejam as olerícolas de forma mais sustentável, mas os agricultores convencionais buscam e utilizam conhecimentos e técnicas para um manejo das olerícolas de menor impacto ao meio ambiente. (Penúltimo parágrafo do texto de criação coletiva da "Colocação em comum").

Em seguida, o monitor perguntou: - "E para vocês, a produção orgânica é uma opção?". Alguns alunos e alunas responderam que sim. Outros levantaram algumas questões, como a Estudante C: - "Mas se você não quiser diversificar muito, se quiser ter poucas culturas, no orgânico você não consegue”. O monitor seguiu questionando: - "E na questão da qualidade de vida? O que vocês acham?". Um aluno respondeu: "Ah, o orgânico oferece mais qualidade de vida, principalmente na saúde". Finalizaram então o último parágrafo do texto coletivo:

O sistema de produção orgânico atualmente é visto como uma alternativa para produção de olerícolas, com maior diversificação. Os benefícios que o sistema traz ao produtor e ao consumidor são diversos, como qualidade de vida e aceitação de mercado. (Último parágrafo do texto de criação coletiva da "Colocação em comum").

Esse texto, chamado de "Síntese", seria posteriormente finalizado pelo monitor para constar no Caderno da Realidade. Além do texto coletivo, cada estudante também redige uma redação individual sobre as suas visitas. 


\section{CONSIDERAÇÕES FINAIS}

A práxis da EFA pesquisada demonstrou como uma Questão Sociocientífica tão controversa quanto o uso de agrotóxicos pode ser discutida em sala de aula, partindo da realidade local e da valorização da experiência dos sujeitos. Em sua dinâmica de alternância e construção do conhecimento pautado no diálogo com a comunidade, a EFASJG oferece uma oportunidade de formação científica-profissional não autoritária, epistemologicamente aberta. Essa abertura se revelou na elaboração de hipóteses, confirmadas (ou não), junto aos agricultores, na elaboração de perguntas pelos próprios alunos, na escuta dos trabalhadores do campo, na elaboração de um texto coletivo (a "Síntese"), baseada em conhecimento adquirido junto à comunidade, na inclusão de todas as respostas (inclusive as contraditórias) na confecção desse texto, e no acolhimento à divergência de opiniões em sala de aula, ainda que o curso seja voltado à agricultura sustentável. Essa vivência do diálogo promove a leitura da realidade partindo do contexto local tornando a escola uma mediadora do debate acerca dos agrotóxicos, para além do livro e da sala de aula.

Na educação científica nas escolas do campo, pensamos não ser possível tratar dessa temática, que impacta tão diretamente a vida dos trabalhadores das roças, sem que se abra para a problematização da realidade vivida por aqueles que lidam diariamente com a questão: o que pensam os camponeses sobre o uso de agrotóxicos? Que alternativas enxergam? Quais os seus constrangimentos? Como favorecer a análise crítica sobre a questão, mediante as inúmeras dificuldades experienciadas pelos homens e mulheres do campo, inclusive no contexto vivenciado pelos pomeranos? Como abrir-se ao diálogo sincero com eles, e potencializar seus esforços em direção a modelos mais sustentáveis de agricultura? Considerar as suas demandas concretas é um importante passo para uma educação que se diga problematizadora e comprometida com o desenvolvimento rural sustentável, sem degradação humana, 
ambiental e social. Por uma sociedade onde plantar e colher se deem, como a Educação, dentro da alegria e da boniteza necessárias.

\section{AGRADECIMENTOS}

Agradecemos à Escola Família Agrícola São João do Garrafão, a todo o seu corpo de funcionários e estudantes, aos estudantes que participaram diretamente deste percurso etnográfico, aos agricultores e agricultoras que abriram suas casas, suas roças e o seu tempo para a realização do Tempo-Comunidade (e desta pesquisa), bem como à Coordenação de Aperfeiçoamento de Pessoal de Nível Superior - Brasil (CAPES) Código de Financiamento 001. 


\section{REFERÊNCIAS}

ABREU, Josyane Barros; STAUDT, Michelli; RIBEIRO, Elinete Oliveira Raposo; FREITAS, Nadia Magalhães da Silva. Agrotóxicos: usá-los ou não? Um estudo de caso no Ensino de Ciências. Ensino de Ciências e Tecnologia em Revista, v. 5 n.2, p. 19-34, 2015.

ANDRADE, Maria Aparecida Silva; CONRADO, Dália Melissa; NUNES-NETO, Nei Freitas; ALMEIDA, Rosiléia Oliveira de. Agrotóxicos como questão sociocientífica na Educação CTSA. Revista Eletrônica do Mestrado em Educação Ambiental, v. 33 n.1, p. 171-191, 2016.

ANDRADE, Maria Aparecida Silva; NUNES-NETO, Nei; ALMEIDA, Rosiléia Oliveira de. Uso de agrotóxicos - Uma Questão Sociocientífica para o Ensino Médio. In: CONRADO, Dália Melissa; NUNES-NETO, Nei (Orgs.), Questões sociocientíficas: fundamentos, propostas de ensino e perspectivas para ações sociopolíticas. 1. ed. Salvador: EDUFBA, 2018 p. 121-144.

ANDRÉ, Marli Eliza D. A. Etnografia da prática escolar. 18. edição. Campinas: Papirus. 2012. 114 p.

AULER, Décio. Novos caminhos para a educação CTS: ampliando a participação. In: SANTOS, Wildson Luiz Pereira dos; AULER, Décio (Orgs.). CTS e educação científica: desafios, tendências e resultados de pesquisas. Brasília: Editora Universidade de Brasília, 2011. p. 73-98.

BRASIL. Decreto no 6.040, de 7 de fevereiro de 2007. Institui a Política Nacional de Desenvolvimento Sustentável dos Povos e Comunidades Tradicionais. Diário Oficial da República, Poder Executivo, Brasília, DF, 2007.

BRICK, Elizandro Maurício; PERNAMBUCO, Marta Maria Castanho; GOUVÊA, Antônio Fernando Gouveia; DELIZOICOV, Demétrio. Paulo Freire: interfaces entre Ensino de Ciências Naturais e Educação do Campo. In: MOLINA, Mônica Castagna (Org.). Licenciaturas em Educação do Campo e o ensino de Ciências Naturais: desafios à promoção do trabalho docente interdisciplinar. Brasília: MDA. 2014. 135 p.

CHISTÉ, Angela; CÓ, Walter. Percepção ambiental de uma comunidade pomerana em relação ao uso de agrotóxicos. Natureza on line, v.1, p.7-11, 2003.

CONRADO, Dália Melissa; NUNES-NETO, Nei. Questões Sociocientíficas e dimensões conceituais, procedimentais e atitudinais dos conteúdos no Ensino de Ciências. In: CONRADO, Dália Melissa; NUNES-NETO, Nei (Orgs.), Questões sociocientíficas: fundamentos, propostas de ensino e perspectivas para ações sociopolíticas. 1. ed. Salvador: EDUFBA, 2018 p. 77-118. 
FERNANDES, Carolina dos Santos; STUANI, Geovana Mulinari. Agrotóxicos no Ensino de Ciências: uma pesquisa na educação do campo. Educação \& Realidade. v. 40 n.3, p.745-762, 2015.

FONSECA, Eril Medeiros da; DUSO, Leandro; HOFFMANN, Marilisa Bialvo. Discutindo a temática agrotóxicos: uma abordagem por meio das controvérsias sociocientíficas. Revista Brasileira de Educação do Campo, v.2 n.3, p.881-898, 2017.

FREIRE, Paulo. Pedagogia do Oprimido. 50. Ed. Rio de Janeiro: Editora Paz e Terra, 2011. 253 p.

FREIRE, Paulo. Extensão ou comunicação? 8. Ed. Rio de Janeiro: Editora Paz e Terra, 1983. $93 \mathrm{p}$.

GIMONET, Jean-Claude. Nascimento e desenvolvimento de um movimento educativo: as Casas Familiares Rurais de Educação e Orientação. In: Pedagogia da Alternância Alternância e Desenvolvimento.2. ed. Brasília: UNEFAB, 1999. p. 39-48.

JACOBSON, Ludmilla da Silva Viana; HACON, Sandra de Souza; ALVARENGA, Luciana; GOLDSTEIN, Roberta Argento; GUMS, Carmem; BUSS, Daniel Forsin; LEDA, Luciana Ribeiro. Comunidade pomerana e o uso de agrotóxicos: uma realidade pouco conhecida. Ciência \& Saúde coletiva, v.14 n.6, p. 2239-2249, 2009.

LOPES, Nataly Carvalho; CARVALHO, Washington Luiz Pacheco de. Agrotóxicos Toxidade versus custos: uma experiência de formação de professores com as Questões Sociocientíficas no Ensino de Ciências. AMAZÔNIA - Revista de Educação em Ciências e Matemáticas, v. 9 n.1), p. 27-48, 2012.

PDI. Plano de Desenvolvimento Institucional - PDI - das Escolas Famílias da Rede MEPES - Unidade Educativa: Escola Família Agrícola de Ensino Fundamental, Médio e Educação Profissional de São João Do Garrafão. São João do Garrafão, 2016.

SILVA, Cícero; GONÇALVES, Adair Vieira. A Etnografia e suas contribuições para o desenvolvimento de uma pesquisa no contexto de ensino da Pedagogia da Alternância. Trab. Ling. Aplic. v.57 n.1, p. 551-578, 2018.

SOUSA, Polliani Santos; GORRI, Ana Paula. Agrotóxicos no Brasil: Uma Visão Relacional a Partir da Articulação Freire-CTS. Revista Brasileira de Pesquisa em Educação em Ciências, v.19 n. 2, p. 399-422, 2019.

SOUZA, Leila Cristina Aoyama Barbosa; MARQUES, Carlos Alberto. Discussões Sociocientíficas sobre o uso de Agrotóxicos: uma atividade formativa problematizada pelo Princípio da Precaução. Revista Brasileira de Pesquisa em Educação em Ciências, v.17 n.2, p. 495-519, 2017.

ZAMBERLAN, Sérgio. MEPES: O início da longa caminhada (1963-1980). Espírito Santo: MEPES, 2018. 283 p. 